\title{
Prevalence of cervical disease at age 20 after immunisation with bivalent HPV vaccine at age 12-13 in Scotland: retrospective population study
}

\author{
Tim Palmer, ${ }^{1}$ Lynn Wallace, ${ }^{2}$ Kevin G Pollock, ${ }^{3,4}$ Kate Cuschieri, ${ }^{5}$ Chris Robertson, ${ }^{3,6,7}$ \\ Kim Kavanagh, ${ }^{7}$ Margaret Cruickshank ${ }^{8}$
}

${ }^{1}$ Department of Pathology, University of Edinburgh,

Edinburgh, UK

${ }^{2}$ Information Services Division, NHS Scotland, Glasgow, UK

${ }^{3}$ Health Protection Scotland, Glasgow, UK

${ }^{4}$ School of Health and Life Science, Glasgow Caledonian University, Glasgow, UK

${ }^{5}$ Scottish Human Papillomavirus Reference Laboratory, Royal Infirmary of Edinburgh,

Edinburgh, UK

${ }^{6}$ International Prevention Research Institute, Lyon, France ${ }^{7}$ Department of Mathematics and Statistics, University of Strathclyde, Glasgow, UK

${ }^{8}$ Institute of Applied Health Services, University of Aberdeen, Aberdeen, UK Correspondence to: T Palmer timothy.palmer@nhs.net (ORCID 0000-0002-3789-1332) Additional material is published online only. To view please visit the journal online.

Cite this as: BMJ 2019;365:11161 http://dx.doi.org/10.1136/bmj.l1161

Accepted: 4 March 2019

\section{ABSTRACT}

OBJECTIVE

To quantify the effect on cervical disease at age 20 years of immunisation with bivalent human papillomavirus (HPV) vaccine at age 12-13 years.

DESIGN

Retrospective population study, 1988-96.

SETTING

National vaccination and cervical screening programmes in Scotland.

\section{PARTICIPANTS}

138692 women born between 1 January 1988 and 5 June 1996 and who had a smear test result recorded at age 20 .

\section{MAIN OUTCOME MEASURES}

Effect of vaccination on cytology results and associated histological diagnoses from first year of screening (while aged 20), calculated using logistic regression.

RESULTS

138692 records were retrieved. Compared with unvaccinated women born in 1988, vaccinated women born in 1995 and 1996 showed an 89\% reduction ( $95 \%$ confidence interval $81 \%$ to $94 \%$ ) in prevalent cervical intraepithelial neoplasia (CIN) grade 3 or worse (from $0.59 \%$ ( $0.48 \%$ to $0.71 \%$ ) to $0.06 \%$ $(0.04 \%$ to $0.11 \%)$ ), an $88 \%$ reduction ( $83 \%$ to $92 \%$ ) in CIN grade 2 or worse (from $1.44 \%$ (1.28\% to $1.63 \%$ ) to $0.17 \%(0.12 \%$ to $0.24 \%)$ ), and a $79 \%$ reduction (69\% to $86 \%$ ) in CIN grade 1 (from $0.69 \%(0.58 \%$ to $0.63 \%)$ to $0.15 \%(0.10 \%$ to $0.21 \%)$ ). Younger age at

\section{WHAT IS ALREADY KNOWN ON THIS TOPIC}

Immunisation against human papillomavirus (HPV) reduces the prevalence of target HPV types and cervical disease in women immunised in catch-up programmes

Population data on the effect on HPV prevalence in women routinely immunised at age 12-13 years show substantial reductions in target and cross protected HPV types

Population data on the effect on disease in routinely immunised women are lacking

\section{WHAT THIS STUDY ADDS}

Routine immunisation using the bivalent HPV vaccine against high grade cervical disease was found to be highly effective

In the setting of high uptake and a catch-up programme, unvaccinated women also show a reduction in disease, possibly because of herd protection

immunisation was associated with increasing vaccine effectiveness: $86 \%$ (75\% to $92 \%$ ) for CIN grade 3 or worse for women vaccinated at age 12-13 compared with $51 \%$ (28\% to $66 \%$ ) for women vaccinated at age 17. Evidence of herd protection against high grade cervical disease was found in unvaccinated girls in the 1995 and 1996 cohorts.

\section{CONCLUSIONS}

Routine vaccination of girls aged $12-13$ years with the bivalent HPV vaccine in Scotland has led to a dramatic reduction in preinvasive cervical disease. Evidence of clinically relevant herd protection is apparent in unvaccinated women. These data are consistent with the reduced prevalence of high risk HPV in Scotland. The bivalent vaccine is confirmed as being highly effective vaccine and should greatly reduce the incidence of cervical cancer. The findings will need to be considered by cervical cancer prevention programmes worldwide.

\section{Introduction}

Cervical carcinoma is the fourth most common cancer in women and a major cause of morbidity and mortality worldwide. ${ }^{1}$ In developed countries where organised cervical screening programmes have been implemented, the incidence and mortality from cervical cancer has decreased, although in many there is either no further diminution or even an increase in incidence. Many factors might contribute to these trends, including decreased uptake of screening, increased rates of human papillomavirus (HPV) infection, and changes in sexual behaviour. ${ }^{23}$ Middle and lower income countries mostly do not have the resources to support organised screening, and cervical cancer remains a considerable problem. The development of vaccines against the most important oncogenic HPV types has the potential to be a major step in the prevention of cervical cancer.

In 2008, Scotland introduced a national immunisation programme against HPV using the bivalent vaccine, which was used until 2012. The immunisation programme was school based, targeted girls aged 12 and 13 (routine vaccination), and was supplemented with a three year catch-up programme to age 18. Uptake in the catch-up cohort was about $65 \%$ overall, but uptake in the routinely immunised cohorts has consistently exceeded $85 \% .^{45}$

Up to and including 5 June 2016, women in Scotland were invited for cervical screening at age 20. Thereafter, they are screened from age 25 . Women from the catch-up cohorts have been screened since 
2010 and women from the routinely immunised cohorts have been screened since 2015. Scotland has comprehensive cervical screening data that contain a woman's entire screening record, immunisation status, and unique personal identifier (community health index (CHI) number). We have been able to show the effectiveness of immunisation on various outcomes, including HPV prevalence, herd immunity, cervical disease, colposcopy outcomes, and uptake of cervical screening. This constitutes a comprehensive programme of immunisation surveillance. ${ }^{6-12}$

Recently we reported on the effect of the bivalent HPV vaccine on prevalence of HPV types in women who were immunised at age 12-13 years and attended for screening at age $20 .^{12}$ In the 1995 birth cohort (associated with 90\% uptake of vaccine at age 13) a virtual eradication of infection related to HPV types 16 and 18 and a statistically significant reduction in cross protective types was observed. Furthermore, no evidence of replacement by other HPV types was evident and statistically significant herd protection in unvaccinated women was identified. Similar reductions have been reported in the Netherlands, where the bivalent vaccine is used. ${ }^{13}$ The considerable reduction in the most carcinogenic HPV types clearly has implications for associated disease and the way it is managed clinically.

In the present study, we report at a national, programme level and through linkage to screening records the effect of routine immunisation of girls aged 12-13 years with the bivalent HPV vaccine on levels of cytological abnormalities and cervical intraepithelial neoplasia (CIN). These findings supplement previous studies in Scotland and the Netherlands, which indicate that the bivalent vaccine will afford protection against most HPV related cervical cancers.

\section{Methods}

\section{Scottish cervical screening programme}

Scotland has an organised, national cervical screening programme, which achieves about $70 \%$ uptake. ${ }^{14} \mathrm{Up}$ to and including 5 June 2016 women aged between 20 and 60 were eligible for screening and thereafter the age range changed to between 25 and 64, 364 days in line with the rest of the United Kingdom. Eligible women are screened every three years until age 50 and then every five years until age 65 . Screening is extended for a further five years if needed to complete follow-up of screen detected abnormalities. Scotland uses Thinprep liquid based cytology with image assisted screening (ThinPrep Imaging System; Hologic, Marlborough, MA). Eight National Health Service cytology laboratories served the programme during the period reported and processed around 400000 samples a year. Cytological and histological findings are classified according to British Association for Cytopathology and NHS cervical screening programme criteria. ${ }^{15} 16$ Table 1 compares the three commonly used reporting systems.

Women are referred for colposcopy after one finding of high grade dyskaryosis or ASCH (atypical squamous cells, cannot rule out high grade squamous intraepithelial lesion), two findings of low grade dyskaryosis or three findings of borderline change during an episode of abnormal follow-up, or three abnormal results in the past 10 years. Women with low grade dyskaryosis or borderline changes are followed up with cytology at six months if not referred for colposcopy. Smear tests are repeated within three months if results are unsatisfactory, and women with three consecutive unsatisfactory results are referred for colposcopy. Ablation or excision is routinely carried out for CIN grade 2 or worse. Conservative management is the expected treatment for low grade disease. Scotland does not use HPV testing for the triage of low grade cytology.

\section{Data extraction, annotation, and exclusions}

The Scottish Cervical Call-Recall System (SCCRS) is a national IT system, which contains comprehensive data relating to screening and acts as an active management tool. We interrogated SCCRS for screening data on all women born between 1 January 1988 and 5 June 1996 from the date of first eligibility for screening (age 20) to the date of data extraction (August 2017). Data extracted included CHI number, postcode of residence, date of birth, attendance, immunisation status, cytology result, colposcopy referral, and related histological diagnosis. The postcode of residence was used to derive the Scottish index of multiple deprivation fifth (where the first fifth represents the most deprived), and rurality index (derived from the Scottish government eight level indicator, with three levels: urban, accessible rural (30-60 minute drive to a settlement of $\geq 10000$ ), and remote rural ( $>60$ minute drive to a settlement of $\geq 10000)$ ). Duplicate records for a woman are linked in SCCRS under the most recent $\mathrm{CHI}$ number, and personal data (including postcode) are updated daily from the Scottish national population register used throughout the Scottish school and healthcare systems.

For all cohorts we restricted the data to those who had cytology tests and colposcopy appointments at age 20. The results for most women corresponded to their first smear test or first colposcopy examination; for the few women with more than one smear test or biopsy in their first year of screening, we used the most severe result. We excluded records without a deprivation and rurality score from analysis. Although data on all screening events were extracted, for this analysis we only used data on attendance in the first year of eligibility, minimising bias resulting from differences in age at time of screening and opportunity for disease detection. Age at immunisation was calculated based on age at first vaccination. Figure 1 shows the relation between immunisation, year of first screen, and data extraction.

\section{Measures of effect and outcomes}

Cytology was recorded as negative (no evidence of disease), borderline (including borderline glandular changes), and low, moderate, or severe grade 


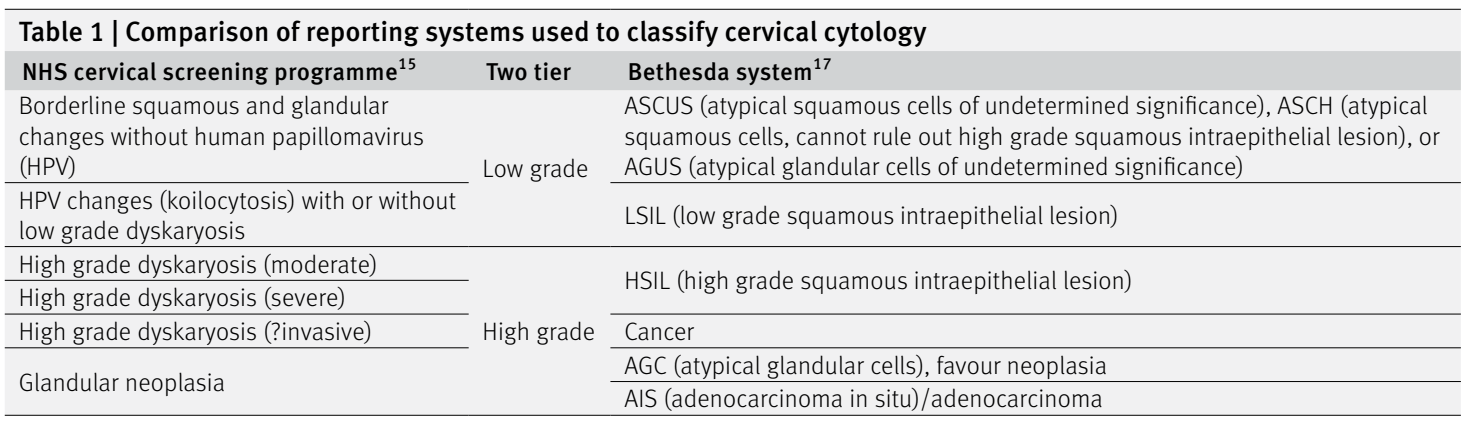

dyskaryosis (including glandular abnormalities). Histology was coded as normal (no CIN detected), CIN grade 1, CIN grade 2, and CIN grade 3 or worse (glandular neoplasia or cancer). We categorised women not referred for colposcopy as having no CIN detected. Wilson's method was used to calculate the confidence intervals for the percentages of women in the outcome groups. We used multivariate multinomial logistic regression models to explore the associations between cytology results, referral for colposcopy and histological diagnosis, and immunisation and demographic variables. Odds ratios for the cytological and histological outcomes are reported with 95\% confidence intervals. Vaccine effectiveness for three doses compared with no doses was calculated as $100 \times(1$-odds ratio), and for those fully vaccinated we estimated vaccine effectiveness separately by age at vaccination with reference to unvaccinated women in the pre-immunisation cohorts (born 1988-90). We used interaction tests to determine if the trend over time was the same between fully vaccinated and unvaccinated women. In addition to the number of doses of vaccine, we investigated the influence of birth cohort, Scottish index of multiple deprivation fifth, and the urban rural indicator on vaccine effectiveness. The pre-immunisation cohorts (born 1988-90) acted as the comparator group, although a small proportion of women born in 1990 were eligible for immunisation. Girls in the catch-up group (1991-94) are more likely to have been exposed to HPV before immunisation, whereas the routinely immunised group (1995-96) are considered more likely to be HPV naïve. We investigated

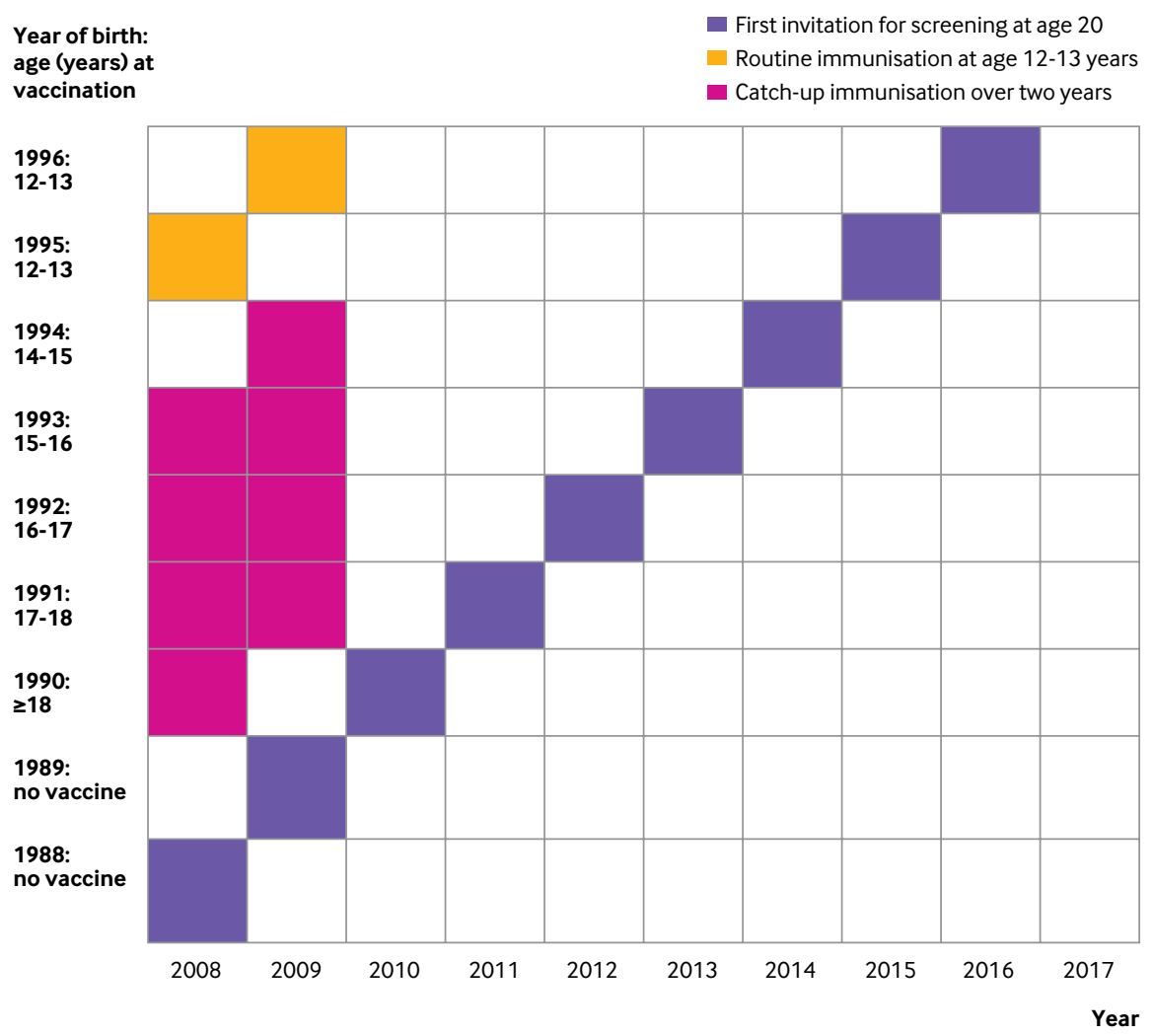

Fig 1 | Schedule of immunisation, screening, and data collection. Only a few birth years in the 1990s were eligible. Girls born in 1994 not covered in first year of catch-up and immunised either side of 15th birthday, depending on date of birth. For first invitation to screening at age 20, women born in 1996 only eligible if date of birth was before 6 June. Data collated for all screening related events in first year of screening. Women born in 1996 had at least 15 months between initial invitation to screening and data extraction 
herd protection by comparing the disease rates among unvaccinated women in the 1991-92, 1993-4, and 1995-96 cohorts with unvaccinated women in the 1989-90 cohort. The statistical analysis was carried out in $\mathrm{R}$ version 3.5.1 and SPSS version 21.

\section{Patient and public involvement}

There was no patient or public involvement in the design or analysis of this study. The records were anonymised before analysis, with preservation of linkage between immunisation, cytology, and histology when appropriate. Caldicott Guardian approval, a UK process to ensure that the use of personal data complies with legal requirements for data protection and is in the public interest, was obtained for the use of data. The data were generated through the routine activity of the Scottish cervical screening programme. Participation in the programme gives implied consent for the use of data derived from this participation for service monitoring and improvement. Management of individual patients is not affected by this study, and no individuals can be identified from the anonymised dataset used by the researchers.

\section{Results}

In total, 138692 women born between 1 January 1988 and 5 June 1996 had a smear test result recorded at age 20. Table 2 and supplementary table 1 show the distribution of the records by year of birth and immunisation status. Three groups are identified, broadly corresponding to unvaccinated women (born 1988-90, age 18-20 in 2008), women vaccinated during the catch-up programme (born 1991-94, age $14-17$ at vaccination), and women routinely vaccinated (born 1995-96, age 12-13 at vaccination). Cumulatively within the extract, 64026 women were unvaccinated and 68480 had three doses of vaccine (fully vaccinated). Only 2051 women received one dose and 4135 women received two doses. The number of women born in 1996 in the dataset is less than in other years as only those born before 6 June were eligible for screening because of changes to the age range for the screening programme. The number of women who had their first dose at age 14 is lower than in other years because of the phasing of the catch-up programme (fig 1).

Tables 3 and 4 show the adjusted odds ratios for cytological and histological outcomes by immunisation status and age at which the first dose was administered and by year of birth in unvaccinated women, respectively. Figures 2 and 3 show the trends in cytological abnormalities and histologically confirmed CIN by percentage of the screened population stratified by no or complete immunisation.

\section{Cytological outcomes}

The overall rate of severe dyskaryosis or worse decreased from $0.75 \%(0.63 \%$ to $0.89 \%)$ for women born in 1988 to $0.06 \%(0.04 \%$ to $0.11 \%)$ for women born in 1995-96, and moderate dyskaryosis decreased from $1.18 \%$ (1.04\% to $1.36 \%$ ) to $0.27 \%$
$(0.21 \%$ to $0.35 \%)$, representing reductions of $92 \%$ (85\% to $95 \%)$ and $77 \%$ (69\% to $83 \%$ ), respectively (table 2). Rates of severe and moderate dyskaryosis in unvaccinated compared with fully vaccinated women born in 1995 and 1996 were not significantly different (fig 2). Overall, borderline/ASCUS rates declined by $34 \%$ (30\% to 39\%), with a similar trend over the cohort in vaccinated and unvaccinated women (interaction test $\mathrm{P}=0.11$ ), although the rate was lower in vaccinated women $(15 \%, 11 \%$ to $19 \%$ ). The reporting of low grade dyskaryosis/LSIL increased during the period of observation. The trend with birth cohort was the same for vaccinated and unvaccinated women (interaction test $\mathrm{P}=0.17$ ); vaccinated women had $19 \%$ (14\% to $24 \%$ ) lower rates (table 2 and fig 2).

Vaccine effectiveness in fully immunised women, vaccinated at ages 12-13, compared with unvaccinated women in $1988-90$ was $42 \%$ (38\% to $46 \%$ ) for borderline/ASCUS, $-38 \%$ ( $-48 \%$ to-28\%) for low grade dyskaryosis/LSIL, 80\% (72\% to $86 \%$ ) for moderate dyskaryosis/HSIL-M, and 93\% (86\% to 97\%) for high grade dyskaryosis/HSIL-H (table 3 ).

\section{Histological outcomes}

High grade CIN showed a significant overall decline (table 2 and fig 2). The rates of CIN grade 3 or worse decreased by $89 \%$ ( $81 \%$ to $94 \%)$, from a preimmunisation rate of $0.59 \%(0.48 \%$ to $0.71 \%)$ in women born in 1988 , to $0.06 \%(0.04 \%$ to $0.11 \%)$ in women born in 1995-96. CIN grade 2 or worse decreased by $88 \%$ (83\% to $92 \%)$, from a preimmunisation rate of $1.44 \%(1.28 \%$ to 1.63$)$, to $0.17 \%$ $(0.12 \%$ to $0.24 \%)$ in women born in $1995-96$. No CIN grade 2 or worse (upper confidence limit $0.7 \%$ ) was found in unvaccinated women in this age group $(n=545)$. The decline in high grade CIN was steeper in fully vaccinated women ( $\mathrm{P}=0.005$ interaction test), but by the 1995-96 cohort, rates of high grade CIN were not significantly different between unvaccinated and vaccinated women ( $\mathrm{P}=0.47$ ) (fig 3).

CIN grade 1 decreased from $0.69 \%(0.58 \%$ to $0.63 \%$ ) of women before immunisation (1988 cohort) to $0.15 \%(0.10 \%$ to $0.21 \%)$ overall for women born in 1995-96: a $79 \%$ (69\% to $86 \%$ ) reduction (table 2 ). The trend over birth cohort was the same for fully immunised and unimmunised women (interaction test $\mathrm{P}=0.90$ ), and there was no evidence that the rates differed between fully immunised and unimmunised women ( $\mathrm{P}=0.17$; fig 3$)$.

For fully immunised women, first vaccinated at age 12-13, vaccine effectiveness for CIN grade 1 was $78 \%$ (66\% to $86 \%$ ), for CIN grade 2 was $89 \%$ ( $81 \%$ to $94 \%$ ), and for CIN grade 3 or worse was $86 \%$ (75\% to $92 \%$ ), compared with unvaccinated women in the 1988-90 cohorts. Vaccine effectiveness was lower for women first vaccinated at age 17: 41\% (14\% to 59\%) for CIN grade $1,56 \%$ (35\% to $70 \%$ ) for CIN grade 2 , and $45 \%$ (17\% to $64 \%$ ) for CIN grade 3 or worse (table 3 ).

Herd protection was observed for the unvaccinated women in the $1995-96$ cohort, with a $63 \%$ reduction in 


\begin{tabular}{|c|c|c|c|c|c|c|c|c|c|c|}
\hline \multirow[b]{2}{*}{ Variables } & \multicolumn{9}{|c|}{ Year of birth } & \multirow[b]{2}{*}{ Total } \\
\hline & 1988 & 1989 & 1990 & 1991 & 1992 & 1993 & 1994 & 1995 & 1996 & \\
\hline No of records & 17589 & 16801 & 17471 & 17618 & 16669 & 16050 & 15854 & 15229 & 5414 & 138692 \\
\hline \multicolumn{11}{|l|}{ Vaccine doses: } \\
\hline 0 & $\begin{array}{l}17579 \\
(99.9)\end{array}$ & $\begin{array}{l}16731 \\
(99.6) \\
\end{array}$ & $\begin{array}{l}14038 \\
(80.4) \\
\end{array}$ & $\begin{array}{l}4994 \\
(28.3) \\
\end{array}$ & $\begin{array}{l}3002 \\
(20.3) \\
\end{array}$ & $\begin{array}{l}3283 \\
(20.3) \\
\end{array}$ & $\begin{array}{l}2209 \\
(13.9) \\
\end{array}$ & $\begin{array}{l}1665 \\
(10.9) \\
\end{array}$ & $\begin{array}{l}545 \\
(10.1) \\
\end{array}$ & $\begin{array}{l}64026 \\
(46.2) \\
\end{array}$ \\
\hline 1 & $3(0.02)$ & $22(0.1)$ & $233(1.4)$ & $538(3.1)$ & $415(2.5)$ & $437(2.7)$ & $267(1.7)$ & $101(0.7)$ & $29(0.5)$ & $2051(1.5)$ \\
\hline 2 & $2(0.01)$ & $18(0.1)$ & $488(2.8)$ & $1196(6.8)$ & $815(5.1)$ & $833(5.2)$ & $548(3.5)$ & $161(1.1)$ & $38(0.7)$ & $4135(3.0)$ \\
\hline 3 & $5(0.03)$ & $30\left(\begin{array}{ll}0 & 2\end{array}\right)$ & $2706(15.5)$ & $\begin{array}{l}10890 \\
(61.8) \\
\end{array}$ & $\begin{array}{l}12401 \\
(74.4)\end{array}$ & $\begin{array}{l}11517 \\
(71.8)\end{array}$ & $\begin{array}{l}12830 \\
(80.9)\end{array}$ & $\begin{array}{l}13229 \\
(87.3)\end{array}$ & $\begin{array}{l}4802 \\
(88.7)\end{array}$ & $\begin{array}{l}68480 \\
(49.4) \\
\end{array}$ \\
\hline \multicolumn{11}{|l|}{ Cytology result: } \\
\hline Negative & $\begin{array}{l}14500 \\
(82.4) \\
\end{array}$ & $\begin{array}{l}13923 \\
(82.9)\end{array}$ & $\begin{array}{l}14302 \\
(81.9) \\
\end{array}$ & $\begin{array}{l}14780 \\
(83.9) \\
\end{array}$ & $\begin{array}{l}14031 \\
(84.2)\end{array}$ & $\begin{array}{l}13640 \\
(85.0)\end{array}$ & $\begin{array}{l}13452 \\
(84.8)\end{array}$ & $\begin{array}{l}13080 \\
(85.9)\end{array}$ & $\begin{array}{l}4656 \\
(86.0) \\
\end{array}$ & $\begin{array}{l}116364 \\
(83.9)\end{array}$ \\
\hline Borderline/ASCUS & $\begin{array}{l}1819 \\
(10.3)\end{array}$ & $\begin{array}{l}1828 \\
(10.9)\end{array}$ & $\begin{array}{l}2102 \\
(12.0)\end{array}$ & $\begin{array}{l}1939 \\
(11.0)\end{array}$ & $\begin{array}{l}1624 \\
(9.8)\end{array}$ & $\begin{array}{l}1143 \\
(7.1)\end{array}$ & $\begin{array}{l}1112 \\
(7.0)\end{array}$ & $\begin{array}{l}1034 \\
(6.8)\end{array}$ & $\begin{array}{l}365 \\
(6.7) \\
\end{array}$ & $\begin{array}{l}12966 \\
(9.3)\end{array}$ \\
\hline Low grade dyskaryosis/LSIL & $929(5.3)$ & $779(4.6)$ & $786(4.5)$ & 694 (3.9) & $869(5.2)$ & $1111(6.9$ & $1178(7.4)$ & $1061(7.0)$ & $375(6.9)$ & $7782(5.6)$ \\
\hline HSIL-M & $208(1.2)$ & $176(1.0)$ & $191(1.1)$ & $137(0.8)$ & $93(0.6)$ & $102(0.6)$ & $76(0.5)$ & $43(0.3)$ & $13(0.2)$ & $1040(0.7)$ \\
\hline HSIL-S+ & $132(0.8)$ & $95(0.6)$ & $90(0.5)$ & $68(0.4)$ & $52(0.3)$ & $54(0.4)$ & $36(0.2)$ & $8(0.1)$ & $5(0.1)$ & $540(0.4)$ \\
\hline Referral for colposcopy & $680(3.9)$ & $612(3.6)$ & $557(3.2)$ & $434(2.5)$ & $355(2.1)$ & 295 (1.9) & $278(1.7)$ & $120(0.8)$ & $20(0.4)$ & $3351(2.4)$ \\
\hline \multicolumn{11}{|l|}{ Histological diagnosis: } \\
\hline CIN grade 1 & $122(0.7)$ & $102(0.6)$ & $98(0.6)$ & $76(0.4)$ & $63(0.4)$ & $60(0.4)$ & $45(0.3)$ & $26(0.2)$ & $4(0.1)$ & $596(.4)$ \\
\hline CIN grade 2 & $151(0.9)$ & $118(0.7)$ & $106(0.6)$ & $75(0.4)$ & $64(0.4)$ & $63(0.4)$ & $38(0.2)$ & $20(0.1)$ & $2(0.04)$ & $637(0.5)$ \\
\hline CIN grade 3 or worse & $103(0.6)$ & $81(0.5)$ & $86(0.5)$ & $66(0.4)$ & $53(0.3)$ & $38(0.2)$ & $29(0.2)$ & $9(0.1)$ & $4(0.1)$ & $469(0.3)$ \\
\hline
\end{tabular}

the odds of CIN grade1 ( $11 \%$ to $85 \%$ ), $67 \%$ reduction for CIN grade 2 (19\% to $86 \%$ ), and $100 \%$ (69\% to $100 \%$ ) reduction for CIN grade 3, compared with unvaccinated women in 1988-90. Similar reductions were noted for moderate dyskaryosis/HSIL-M (58\%, $21 \%$ to $78 \%$ ) and high grade dyskaryosis/HSIL-H (85\%, 38\% to $96 \%$ ) but not for borderline/ASCUS or low grade dyskaryosis/LSIL (table 4).

\section{One and two dose outcomes}

Tables 2 and 3 show the number of women with one dose or two doses of vaccine and outcomes. Although reductions occurred in both cytological and histological outcomes with two doses, no statistically significant effect was seen for either one dose or two doses. The numbers were too small to allow analysis by year of birth.

\begin{tabular}{|c|c|c|c|c|c|c|c|c|c|}
\hline \multirow{2}{*}{$\begin{array}{l}\text { Age groups } \\
\text { and dose }\end{array}$} & \multirow{2}{*}{$\begin{array}{l}\text { Years to first } \\
\text { screen }\end{array}$} & \multirow[b]{2}{*}{ No } & \multirow{2}{*}{$\begin{array}{l}\text { Borderline } \\
\text { changes }\end{array}$} & \multirow{2}{*}{$\begin{array}{l}\text { Low grade } \\
\text { dyskaryosis }\end{array}$} & \multicolumn{2}{|c|}{ High grade dyskaryosis } & \multicolumn{3}{|l|}{ CIN grade } \\
\hline & & & & & Moderate & Severe & 1 & 2 & 3 or worse \\
\hline All: 1 dose & & 2051 & $\begin{array}{l}0.94 \\
\text { (0.81 to } 1.08)\end{array}$ & $\begin{array}{l}1.27 \\
\text { (1.05 to } 1.53)\end{array}$ & $\begin{array}{l}0.89 \\
(0.58 \text { to } 1.37)\end{array}$ & $\begin{array}{l}1.02 \\
(0.59 \text { to } 1.75) \\
\end{array}$ & $\begin{array}{l}0.94 \\
(0.53 \text { to } 1.68) \\
\end{array}$ & $\begin{array}{l}0.95 \\
(0.56 \text { to } 1.59) \\
\end{array}$ & $\begin{array}{l}1.19 \\
(0.70 \text { to } 2.05) \\
\end{array}$ \\
\hline All: 2 doses & & 4135 & $\begin{array}{l}0.94 \\
(0.85 \text { to } 1.04)\end{array}$ & $\begin{array}{l}1.09 \\
(0.94 \text { to } 1.26)\end{array}$ & $\begin{array}{l}0.91 \\
(0.67 \text { to } 1.24)\end{array}$ & $\begin{array}{l}0.62 \\
(0.38 \text { to } 1.00)\end{array}$ & $\begin{array}{l}0.70 \mid \\
(0.43 \text { to } 1.12)\end{array}$ & $\begin{array}{l}0.70 \\
(0.45 \text { to } 1.07)\end{array}$ & $\begin{array}{l}0.77 \\
(0.48 \text { to } 1.24)\end{array}$ \\
\hline \multicolumn{10}{|l|}{3 doses: } \\
\hline 12 and 13 & 7 or 8 & 16200 & $\begin{array}{l}0.58 \\
(0.54 \text { to } 0.62)\end{array}$ & $\begin{array}{l}1.38 \\
(1.28 \text { to } 1.48)\end{array}$ & $\begin{array}{l}0.20 \\
(0.15 \text { to } 0.28)\end{array}$ & $\begin{array}{l}0.07 \\
(0.03 \text { to } 0.14)\end{array}$ & $0.22(.14$ to 0.34$)$ & $\begin{array}{l}0.11 \\
(0.06 \text { to } 0.19)\end{array}$ & $\begin{array}{l}0.14 \\
(0.08 \text { to } 0.25)\end{array}$ \\
\hline 14 & 6 & 5409 & $\begin{array}{l}0.55 \\
(0.50 \text { to } 0.62)\end{array}$ & $\begin{array}{l}1.37 \\
(1.22 \text { to } 1.53)\end{array}$ & $\begin{array}{l}0.26 \\
(0.16 \text { to } 0.42)\end{array}$ & $\begin{array}{l}0.23 \\
(0.11 \text { to } 0.46)\end{array}$ & $\begin{array}{l}0.48 \\
(0.29 \text { to } 0.79)\end{array}$ & $\begin{array}{l}0.13 \\
(0.05 \text { to } 0.31)\end{array}$ & $\begin{array}{l}0.18 \\
(0.07 \text { to } 0.43)\end{array}$ \\
\hline 15 & 5 & 16532 & $\begin{array}{l}0.59 \\
\text { (0.55 to } 0.63)\end{array}$ & $\begin{array}{l}1.31 \\
(1.22 \text { to } 1 \\
41)\end{array}$ & $\begin{array}{l}0.36 \\
(0.28 \text { to } 0.47)\end{array}$ & $\begin{array}{l}0.28 \\
(0.20 \text { to } 0.41)\end{array}$ & $\begin{array}{l}0.48 \\
(0.36 \text { to } 0.65)\end{array}$ & $\begin{array}{l}0.35 \\
(0.25 \text { to } 0.48)\end{array}$ & $\begin{array}{l}0.29 \\
(0.19 \text { to } 0.44)\end{array}$ \\
\hline 16 & 4 & 17511 & $\begin{array}{l}0.75 \\
\text { (0.71 to } 0.80)\end{array}$ & $\begin{array}{l}1.05 \\
(0.97 \text { to } 1.13)\end{array}$ & $\begin{array}{l}0.35 \\
(0.27 \text { to } 0.45)\end{array}$ & $\begin{array}{l}0.25 \\
(0.17 \text { to } 0.37)\end{array}$ & $\begin{array}{l}0.58 \\
(0.44 \text { to } 0.77)\end{array}$ & $\begin{array}{l}0.31 \\
(0.23 \text { to } 0.44)\end{array}$ & $\begin{array}{l}0.27 \\
(0.18 \text { to } 0 \\
41)\end{array}$ \\
\hline 17 & 3 & 8711 & $\begin{array}{l}0.86 \\
\text { (0.80 to } 0.93)\end{array}$ & $\begin{array}{l}0.77 \\
(0.96 \text { to } 0.86)\end{array}$ & $\begin{array}{l}0.60 \\
(0.46 \text { to } 0.78)\end{array}$ & $\begin{array}{l}0.42 \\
(0.27 \text { to } 0.63)\end{array}$ & $\begin{array}{l}0.59 \\
(0.41 \text { to } 0.86)\end{array}$ & $\begin{array}{l}0.45 \\
(0.30 \text { to } 0.66)\end{array}$ & $\begin{array}{l}0.55 \\
(0.36 \text { to } 0.83)\end{array}$ \\
\hline$\geq 18$ & 2 & 4117 & $\begin{array}{l}0.98 \\
\text { (0.89 to } 1.08)\end{array}$ & $\begin{array}{l}0.80 \\
(0.68 \text { to } 0.94)\end{array}$ & $\begin{array}{l}0.65 \\
(0.45 \text { to } 0.93)\end{array}$ & $\begin{array}{l}0.88 \\
\text { (0.58 to } 1.35)\end{array}$ & $\begin{array}{l}0.79 \\
(0.50 \text { to } 1.25)\end{array}$ & $\begin{array}{l}0.75 \\
\text { (0.48 to } 1.15)\end{array}$ & $\begin{array}{l}0.85 \\
(0.52 \text { to } 1.37)\end{array}$ \\
\hline z1991: 0 doses & & 15678 & $\begin{array}{l}0.89 \\
\text { (0.84 to } 0.94)\end{array}$ & $\begin{array}{l}1.41 \\
\text { (1.31 to } 1.52)\end{array}$ & $\begin{array}{l}0.84 \\
(0.70 \text { to } 1.01)\end{array}$ & $\begin{array}{l}0.90 \\
(0.71 \text { to } 1.14)\end{array}$ & $\begin{array}{l}0.62 \\
(0.47 \text { to } 0.82)\end{array}$ & $\begin{array}{l}0.81 \\
\text { (0.65 to } 1.02)\end{array}$ & $\begin{array}{l}0.82 \\
\text { (0.63 to } 1.07 \text { ) }\end{array}$ \\
\hline $\begin{array}{l}\text { 1988-90: } 0 \\
\text { doses }\end{array}$ & & 48348 & 1.00 & 1.00 & 100 & 1.00 & 1.00 & 1.00 & 1.00 \\
\hline
\end{tabular}

$\mathrm{CIN}=$ cervical intraepithelial neoplasia.

Estimates derived from multinomial regression model adjusting also for deprivation and rurality. Estimated effects of these variables were similar to those in supplementary table 1 and are not repeated here. 


\begin{tabular}{|c|c|c|c|c|c|c|c|c|}
\hline \multirow{2}{*}{$\begin{array}{l}\text { Year of } \\
\text { birth: age } \\
\text { (years) }\end{array}$} & \multirow{2}{*}{$\begin{array}{l}\text { No of } \\
\text { women }\end{array}$} & \multirow{2}{*}{$\begin{array}{l}\text { Borderline } \\
\text { changes }\end{array}$} & \multirow{2}{*}{$\begin{array}{l}\text { Low grade } \\
\text { dyskaryosis }\end{array}$} & \multicolumn{2}{|c|}{ High grade dyskaryosis } & \multicolumn{3}{|l|}{ CIN grade } \\
\hline & & & & Moderate & Severe & 1 & 2 & 3 or worse \\
\hline $\begin{array}{l}\text { 1995-96: } \\
12-13\end{array}$ & 2210 & $0.64(0.55$ to 0.76$)$ & 1.62 (1.38 to 1.90$)$ & $0.42(0.23$ to 0.79$)$ & 0.15 (0.04 to 0.62$)$ & $0.37(0.15$ to 0.89$)$ & 0.34 (0.14 to 0.81$)$ & $0.00\left(0.00\right.$ to $\left.0.31^{\star}\right)$ \\
\hline $\begin{array}{l}\text { 1993-94: } \\
14 \text { or } 15\end{array}$ & 5472 & 0.75 (0.68 to 0.83$)$ & 1.70 (1.53 to 1.89$)$ & $0.81(0.60$ to 1.08$)$ & $1.11(0.79$ to 1.56$)$ & $0.53(0.33$ to 0.86$)$ & $0.78(0.54$ to 1.13$)$ & $0.76(0.49$ to 1.18$)$ \\
\hline $\begin{array}{l}\text { 1991-92: } \\
16 \text { or } 17\end{array}$ & 7996 & 1.05 (0.97 to 1.13$)$ & 1.16 (1.04 to 1.28$)$ & 0.98 (0.78 to 1.23$)$ & $0.95(0.70$ to 1.28$)$ & $0.74(0.5301 .05$ & 0.97 (0.73 to 1.29$)$ & 1.07 (0.78 to 1.47$)$ \\
\hline $\begin{array}{l}\text { 1988-90: } \\
\geq 18\end{array}$ & 48348 & 1.00 & 1.00 & 1.00 & 1.00 & 1.00 & 1.00 & 1.00 \\
\hline
\end{tabular}

$\mathrm{CIN}=$ cervical intraepithelial neoplasia.

Estimates derived from multinomial regression model, adjusted for deprivation and rurality using data only from unvaccinated women. $1988-90$ cohorts were not eligible for vaccine.

*Estimate based on Fisher's exact test.

\section{Discussion}

This study reports statistically significant reductions in all grades of cervical intraepithelial neoplasia (CIN), equating to vaccine effectiveness estimates of $80 \%$ or greater after routine immunisation at age 12 13 years. The prevalence of high grade dyskaryosis was similarly reduced. Herd protection has been shown in unvaccinated women in the cohort offered routine immunisation. The changes in cytological abnormality and histologically confirmed cervical disease in women attending for their first cervical screen aged 20 associated with routine vaccination at age 12-13 years with the bivalent human papillomavirus (HPV) vaccine in a setting that offered both a catch-up programme and that achieved high and consistent uptake. The results of this study were derived from data that directly link immunisation status and screening outcome at the level of the individual. We are confident that the reduction in disease does not relate to the inability of cytological screening to detect disease in vaccinated women, given previous data on cytology performance that showed no loss of sensitivity in vaccinated compared with unvaccinated women, and the deterioration in the clinical significance or positive predictive value of cytologically defined low grade disease described elsewhere. $^{5}$

The increase in reporting of low grade dyskaryosis/ LSIL in immunised women was statistically significant, in contrast with the reduction in all other cytological categories and all grades of CIN. Scottish surveillance data indicate that vaccine types and cross protected

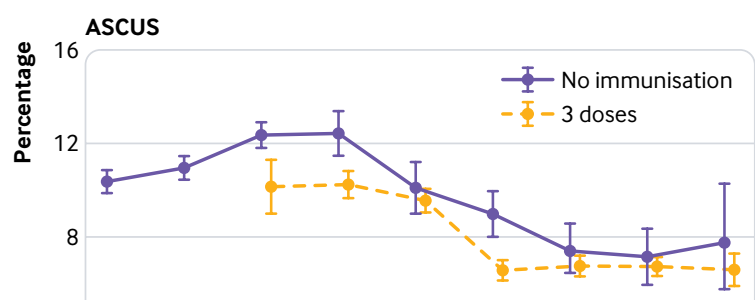

4

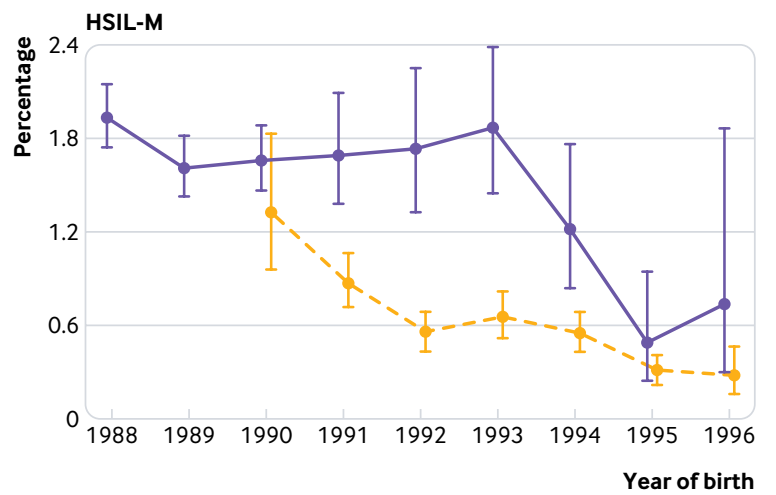

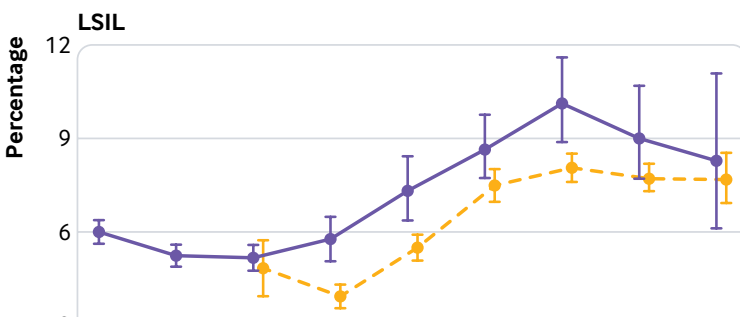

3

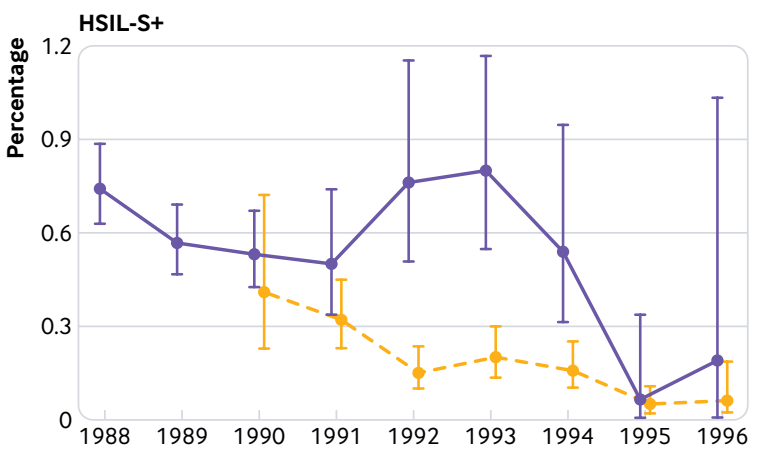

Fig 2 | Cytological abnormality (\% of women screened) by year of birth and immunisation status. 1988-90=pre-immunisation programme cohort; 1991-94=catch-up cohort; 1995-96=routinely immunised cohort. Whiskers represent 95\% confidence intervals. ASCUS=atypical squamous cells of undetermined significance; LSIL=low grade squamous intraepithelial lesion; HSIL=high grade squamous intraepithelial lesion (HSIL-M=mild dyskaryosis; HSIL-S+=severe dyskaryosis) 

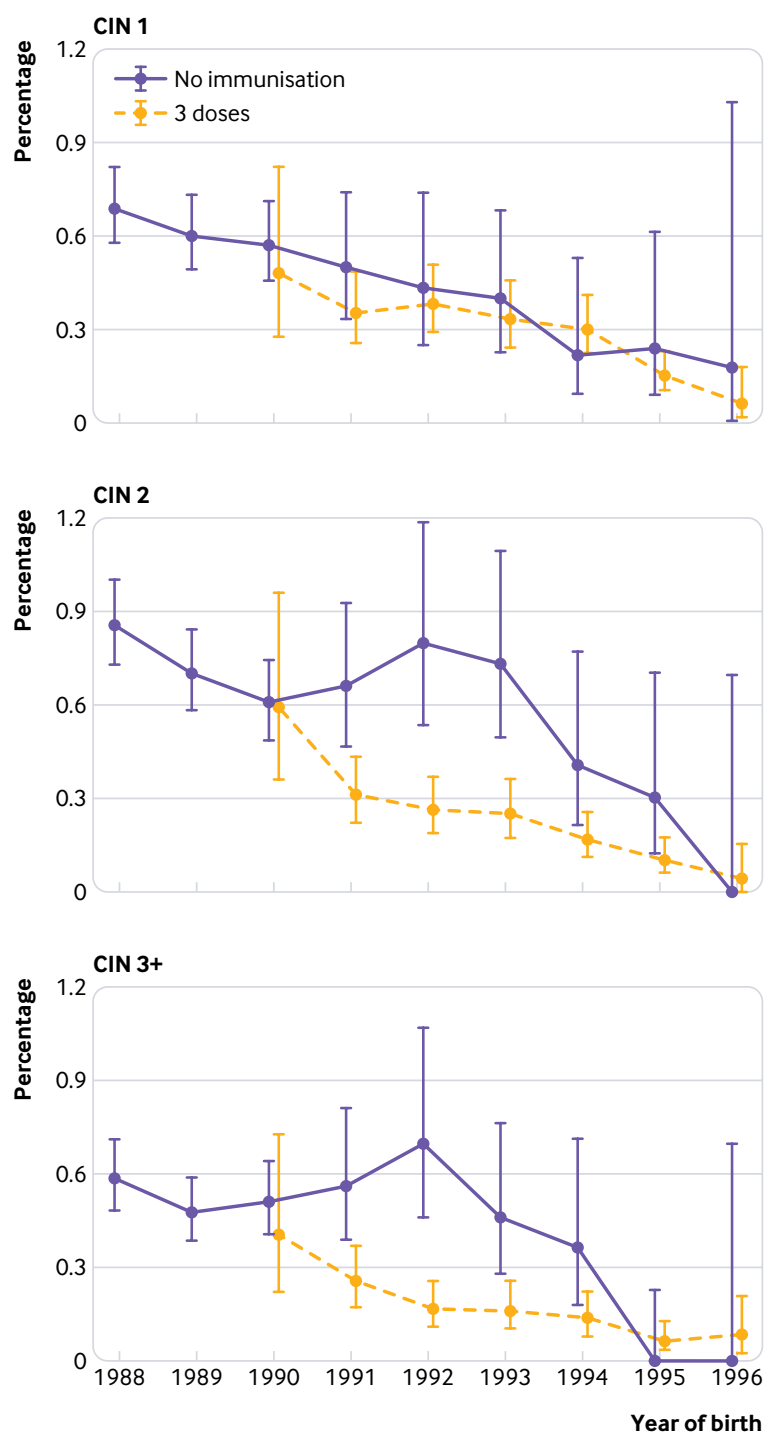

Fig 3 | Histological abnormality (\% of women screened) by year of birth and immunisation status. Whiskers represent $95 \%$ confidence intervals. $\mathrm{CIN}=$ cervical intraepithelial neoplasia; $1988-90=$ pre-immunisation programme cohort; 1991-94=catch-up cohort; 1995-96=routinely immunised cohort

types (HPV 16, 18, 31, 33, and 45) are found in a higher proportion of samples with borderline/ASCUS cytology than in samples with low grade dyskaryosis/ LSIL cytology and this could, in part, explain this observation. The human papillomavirus (HPV) types that remain after immunisation might not be associated with persistent disease. The cytological differential diagnosis of borderline/ASCUS changes is often moderate dykaryosis/HSIL rather than low grade dyskaryosis/LSIL (cases of borderline, atypical squamous cells, cannot rule out high grade squamous intraepithelial lesion (ASCH) are reported but not recorded separately). Also, changes have occurred in the classification of HPV related cytological changes, and the management of CIN grade 1 or less at colposcopy that will have affected the relation between low grade cytology and a diagnosis of CIN grade 1 .

\section{Strengths and limitations of this study}

The strengths of this study include direct linkage of data between immunisation status and screening outcomes, and that the data are from the screened population rather than a selected cohort. The completeness of the screening database and the longstanding, organised nature of the surveillance programme means that it is possible to show trends and to examine their correlation to several variables. The data therefore form a sound basis for development of cervical cancer prevention strategies.

This study has limitations. The analysis was confined to women attending for cervical screening at age 20. Uptake of screening in fully vaccinated women aged 20 or 21 is $51 \%$, and only $23 \%$ in unvaccinated women. ${ }^{14}$ It is possible therefore that vaccine effectiveness was over-estimated. However, the high uptake of vaccination, similarity in distribution of HPV type in attenders and non-attenders, and appearance of herd protection give reassurance that the observations can be extrapolated to the general population. $^{19}$

The shorter follow-up time for women born in 1995 and 1996 necessarily affects the robustness of the estimation of vaccine effectiveness for younger women; however, further planned longitudinal studies will help elucidate true protection from the effects of routine vaccination. The formal adoption of a conservative management protocol for women with CIN grade 1 at colposcopy over the study period could have affected the numbers of biopsies carried out. However, it is unlikely that this change in practice accounted for the magnitude of the reductions in CIN grade 1 , particularly when considered along with the reductions in CIN grades 2 and 3, for which there were no changes in clinical management or treatment over the study period.

CIN grade 3 is now considered the best predictor of risk of invasive cancer, but a proportion will still regress. It is known that the likelihood of developing CIN grade 3 varies with the HPV genotype and is highest with HPV types 16,31 , and $33 .^{20}$ The propensity for the CIN to regress is also related to the HPV type, and there are fewer cancers attributable to HPV type 33 than would be expected from the prevalence of this genotype in CIN grade 3 lesions. $^{21}$ As the most oncogenic types have been effectively removed from the population it might be that regression of CIN grade 3 is more likely in vaccinated women, increasing vaccine effect on rates of CIN grade 3.

Another unavoidable limitation of high compliance with full vaccine schedules is the inability to assess the impact of fewer than three doses. The characteristics of partially immunised women in Scotland have been described previously. ${ }^{5}$ Briefly, partial immunisation was associated with increased deprivation, having left school, and increasing age. In girls offered routine, in-school vaccination, only $1.6 \%$ were partially immunised compared with $9.8 \%$ in the first full year of catch-up. 


\section{Comparison with other studies}

These results are the clinical counterpart of the reductions in type specific HPV infection shown in routinely vaccinated women. ${ }^{12}$ Kavanagh and colleagues showed statistically significant vaccine effectiveness against HPV types 16 and 18 (90\%) and cross protective HPV types (80-85\%), with cross protection lasting a minimum of seven years. Herd protection against HPV 16 and 18 related infection was also found in unvaccinated women in the routine vaccination cohort. The reduction of CIN grade 3 and the estimates of vaccine effectiveness reported are of a similar magnitude to those reported by Kavanagh and colleagues for HPV infection. ${ }^{12}$ The vaccine specific and cross protected HPV types covered by the vaccine (HPV 16, 18, 31, 33, and 45) are implicated in 90\% of cancers in Scotland. ${ }^{22}$ CIN grade 3 is the precursor of invasive cervical carcinoma, with the least diagnostic variability and lowest rate of spontaneous regression, and it is recognised as the best indicator of the risk of invasive cancer. ${ }^{23-25}$ It is therefore reasonable to expect that the reduction in CIN grade 3 will lead to a reduction in cervical cancer in future years. The anticipated impact of immunisation on cancer will take more time to become apparent.

A recent Cochrane review of the effectiveness of bivalent and quadrivalent HPV vaccination in randomised trials has shown unequivocal, high quality evidence of the benefits of immunisation. ${ }^{26}$ Our results are in keeping with this review. Population studies in other settings have shown a major impact of the quadrivalent vaccine on infection and associated benign and neoplastic disease. ${ }^{27-34}$ The present work complements these studies in being the first to report on the impact of the bivalent vaccine on disease when delivered to girls aged 12-13 years within a national programme. It will now be of interest to see the impact of the nonavalent vaccine at the population level. It is postulated that the nonavalent vaccine will protect against $90 \%$ of cervical cancers globally. ${ }^{35}$ However, worthwhile additional protection against cancer because of the nonavalent vaccine will be difficult to show in Scotland, given the distribution of HPV types in the UK, the effect of the bivalent vaccine, and the absence of type replacement to date, although the effect on genital warts is clear. ${ }^{27}$ The Scottish cervical screening programme is incorporating HPV immunisation into its routine programme monitoring statistics. This, along with the projected move to HPV primary screening, will facilitate the monitoring of changes in vaccine effectiveness in the future.

\section{Policy implications}

Low levels of cervical cancer after routine vaccination clearly have ramifications for screening vaccinated women. Although major disease is reduced in Scotland, it has not been eradicated, and continued screening is therefore necessary, particularly as for some years most women within the screening programme will not have been vaccinated. Previous work has suggested that the performance of cytology based and HPV based screening deteriorates in vaccinated women, despite preservation of sensitivity. ${ }^{78}$ This can be attributed to reduced disease levels leading to a higher number of false positive test results and a lower positive predictive value for important disease. The effectiveness of HPV primary screening in highly immunised populations will need close monitoring. Novel methods for improving uptake of screening, the effectiveness of the screening and, crucially, the triage test will be needed to maintain the performance of cervical screening as a process. The reduced rate of disease in those referred for colposcopy will likewise make the maintenance of colposcopy standards challenging. ${ }^{10}$

${ }^{11}$ Different modelling approaches have been used to inform optimal scenarios for screening of vaccinated women but have converged on the conclusion that, for some women, two or three screens in a lifetime using HPV testing might be sufficient. ${ }^{36} 37$ Such sporadic screening, coupled with much reduced disease and decreasing numbers of women referred for colposcopy and treatment, necessitates redesign of cervical screening programmes. Ultimately, the clinical and economic rationale for cervical screening will need to be reviewed.

\section{Conclusion}

We have presented linked data, from a population with high vaccine uptake and a comprehensive catch-up programme, which show routine immunisation with three doses of bivalent vaccine at age 12-13 years is associated with a profound reduction of cervical disease seven years later, measured by cytological and histological abnormalities and referral for colposcopy. Disease was also reduced in unvaccinated women, possibly because of herd protection. Routinely vaccinated populations will also have a lower risk of other HPV related diseases. ${ }^{38}$ The reduction in disease in routinely immunised women, who will form the bulk of the screened population in years to come, mandates revision of screening and referral guidelines. The findings emphasise the credibility of using high risk HPV infection as an early marker of the effectiveness and success of the vaccine and underpin the recent call for global action on cervical cancer from the World Health Organization.

The manuscript was reviewed by Jo's Trust, which supports the conclusions. It made the following statement: We think (it has) massive implications for the screening programme, vaccine and also impact on diagnoses in the future. It gives weight for activity to increase vaccine uptake, has implications on screening intervals. The clinically relevant herd protection is very interesting too. It also feeds into our policy calls for a new IT infrastructure (for the screening programme in England) to record and enable invitations based on whether someone has at the vaccine if intervals can be extended.

Contributors: TP was the lead author, conducted the literature search, produced the initial drafts, and collated comments. He specified the data extracted and worked with LW, CR, and the Cervical Screening system managers to confirm the quality of the extracted data. TP is the guarantor for this study. LW undertook the data analysis under the guidance of CR and reviewed early drafts. CR directed the statistical analysis and reviewed successive drafts. KC and KP provided support with analysis or interpretation, contextualisation, and generation of manuscript drafts. KK and MC provided additional statistical and clinical input and reviewed the later drafts. The corresponding author 
attests that all listed authors meet authorship criteria and that no others meeting the criteria have been omitted.

Funding: This study has been undertaken as part of the programme of surveillance of immunisation against human papillomavirus in Scotland, included within the routine work of Health Protection Scotland, a part of the Scottish National Health Service. No funding has been received from industry.

Competing interests: All authors have completed the ICMJE uniform disclosure form at www.icmje.org/coi_disclosure.pdf and declare: $\mathrm{KP}$ has received travel monies from both Merck and GSK to attend conferences. KC's institution has received monies to deliver research, or associated consumables to support research, from: Qiagen, Hologic, Selfscreen, GeneFirst, Euroimmun, Cepheid, Genomica, and LifeRiver. No personal conflicts of interest are declared.

Ethical approval: No ethical approval was required for this study as patient treatment was not altered by the observations. Caldicott approval for use of personal data was obtained.

Data sharing: No additional data available.

Transparency: The manuscript's guarantor (TP) affirms that this manuscript is an honest, accurate, and transparent account of the study being reported; that no important aspects of the study have been omitted; and that any discrepancies from the study as planned (and, if relevant, registered) have been explained.

This is an Open Access article distributed in accordance with the Creative Commons Attribution Non Commercial (CC BY-NC 4.0) license, which permits others to distribute, remix, adapt, build upon this work non-commercially, and license their derivative works on different terms, provided the original work is properly cited and the use is noncommercial. See: http://creativecommons.org/licenses/by-nc/4.0/.

1 GLOBOCAN Cervical cancer fact sheet. http://globocan.iarc.fr/Pages/ fact_sheets_cancer.aspx

2 Mercer $\mathrm{CH}$, Tanton C, Prah P, et al. Changes in sexual attitudes and lifestyles in Britain through the life course and over time: findings from the National Surveys of Sexual Attitudes and Lifestyles (Natsal). Lancet 2013;382:1781-94. doi:10.1016/S0140-6736(13)62035.

3 Cancer Research UK. www.cancerresearchuk.org/health-professional/ cancer-statistics/statistics-by-cancer-type/cervical-cancer/diagnosisand-treatment\#heading-Eight.

4 Information Services Division. Scotland. Estimate of HPV vaccine uptake in Scotland, by year of birth. https://isdscotland.scot.nhs. uk/Health-Topics/Child-Health/publications/data-tables2017. asp?id=2048\#2048.

5 Sinka K, Kavanagh K, Gordon R, et al. Achieving high and equitable coverage of adolescent HPV vaccine in Scotland. J Epidemiol Community Health 2014;68:57-63. doi:10.1136/jech-2013 202620

6 Pollock KG, Kavanagh K, Potts A, et al. Reduction of low- and highgrade cervical abnormalities associated with high uptake of the HPV bivalent vaccine in Scotland. Br J Cancer 2014;111:1824-30. doi:10.1038/bjc.2014.479

7 Palmer TJ, McFadden M, Pollock KG, et al. HPV immunisation and cervical screening--confirmation of changed performance of cytology as a screening test in immunised women: a retrospective populationbased cohort study. Br J Cancer 2016;114:582-9. doi:10.1038/ bjc. 2015.474

8 Bhatia R, Kavanagh K, Cubie HA, et al. Use of HPV testing for cervical screening in vaccinated women--Insights from the SHEVa (Scottish HPV Prevalence in Vaccinated Women) study. Int J Cancer 2016:138:2922-31. doi:10.1002/ijc.30030

9 Kavanagh K, Pollock KG, Potts A, et al. Introduction and sustained high coverage of the HPV bivalent vaccine leads to a reduction in prevalence of HPV 16/18 and closely related HPV types. $\mathrm{Br}$ Cancer 2014;110:2804-11. doi:10.1038/bjc.2014.198

10 Cruickshank ME, Pan J, Cotton SC, et al. Reduction in colposcopy workload and associated clinical activity following human papillomavirus (HPV) catch-up vaccination programme in Scotland: an ecological study. BJOG 2017;124:1386-93. doi:10.1111/1471 0528.14562

11 Munro A, Gillespie C, Cotton S, et al. The impact of human papillomavirus type on colposcopy performance in women offered HPV immunisation in a catch-up vaccine programme: a two-centre observational study. BJOG 2017;124:1394-401. doi:10.1111/1471-0528.14563

12 Kavanagh K, Pollock KG, Cuschieri K, et al. Changes in the prevalence of human papillomavirus following a national bivalent human papillomavirus vaccination programme in Scotland: a 7-year crosssectional study. Lancet Infect Dis 2017;17:1293-302. doi:10.1016/ S1473-3099(17)30468-1
13 Donken R, King AJ, Bogaards JA, Woestenberg PJ, Meijer CJLM, de Melker HE. High Effectiveness of the Bivalent Human Papillomavirus (HPV) Vaccine Against Incident and Persistent HPV Infections up to 6 Years After Vaccination in Young Dutch Women. J Infect Dis 2018;217:1579-89. doi:10.1093/infdis/jiy067

14 Information Services Division. Scotland. www.isdscotland.org/HealthTopics/Cancer/Cervical-Screening/.

15 Denton K. The proposed BSCC terminology for abnormal cervical cytology. Cytopathology 2008;19:398-9. doi:10.1111/j.13652303.2008.00624.x

16 Colposcopy and programme management: guidelines for the NHS CervicalScreening Programme. NHS CSP Document 20. 2nd edn (2010) www.cancerscreening.nhs.uk/cervical/publications/ nhscsp20.html.

17 Nayar R, Wilbur DC. The Pap Test and Bethesda 2014. "The reports of my demise have been greatly exaggerated." (after a quotation from Mark Twain). Acta Cytol 2015;59:121-32. doi:10.1159/000381842

18 Palmer TJ, McFadden M, Pollock KG, et al. HPV immunisation and increased uptake of cervical screening in Scottish women; observational study of routinely collected national data. $\mathrm{Br}$ Cancer 2016;114:576-81. doi:10.1038/bjc.2015.473

19 Kavanagh K, Sinka K, Cuschieri K, et al. Estimation of HPV prevalence in young women in Scotland; monitoring of future vaccine impact. BMC Infect Dis 2013;13:519. doi:10.1186/1471-2334-13-519

20 Cuzick J, Wheeler C. Need for expanded HPV genotyping for cervical screening. Papillomavirus Res 2016;2:112-5.

21 Carcopino X, Bolger N, Henry M, et al. Evaluation of type-specific HPV persistence and high-risk HPV viral load quantitation in HPV positive women under 30 with normal cervical cytology. J Med Virol 2011:83:637-43. doi:10.1002/jmv.22022

22 Mesher D, Cuschieri K, Hibbitts S, et al. Type-specific HPV prevalence in invasive cervical cancer in the UK prior to national HPV immunisation programme: baseline for monitoring the effects of immunisation. J Clin Pathol 2015;68:135-40. doi:10.1136/ jclinpath-2014-202681

23 Carreon JD, Sherman ME, Guillén D, et al. CIN2 is a much less reproducible and less valid diagnosis than CIN3: results from a histological review of population-based cervical samples. Int J Gynecol Pathol 2007;26:441-6. doi:10.1097/ pgp.0b013e31805152ab

24 Castle PE, Schiffman M, Wheeler CM, Solomon D. Evidence for frequent regression of cervical intraepithelial neoplasiagrade 2. Obstet Gynecol 2009;113:18-25. doi:10.1097/ AOG.Ob013e31818f5008

25 Lee MH, Finlayson S), Gukova K, Hanley G, Miller D, Sadownik LA. Outcomes of Conservative Management of High Grade Squamous Intraepithelial Lesions in Young Women. J Low Genit Tract Dis 2018;22:212-8. doi:10.1097/LGT.0000000000000399

26 Arbyn M, Xu L, Simoens C, Martin-Hirsch PP. Prophylactic vaccination against human papillomaviruses to prevent cervical cancer and its precursors. Cochrane Database Syst Rev 2018;5:CD009069.

27 Garland SM, Kjaer SK, Muñoz N, et al. Impact and Effectiveness of the Quadrivalent Human Papillomavirus Vaccine: A Systematic Review of 10 Years of Real-world Experience. Clin Infect Dis 2016;63:519-27. doi:10.1093/cid/ciw354

28 Herweijer E, Sundström K, Ploner A, Uhnoo I, Sparén P, ArnheimDahlström L. Quadrivalent HPV vaccine effectiveness against high-grade cervical lesions by age at vaccination: A population-based study. Int J Cancer 2016;138:2867-74. doi:10.1002/ijc.30035

29 Hariri S, Markowitz LE, Bennett NM, et al, Hpv-Impact Working Group. Monitoring Effect of Human Papillomavirus Vaccines in US Population, Emerging Infections Program, 2008-2012. Emerg Infect Dis 2015;21:1557-61. doi:10.3201/eid2109.141841

30 Smith LM, Strumpf EC, Kaufman JS, Lofters A, Schwandt M, Lévesque LE. The early benefits of human papillomavirus vaccination on cervical dysplasia and anogenital warts. Pediatrics 2015;135:e113140. doi:10.1542/peds.2014-2961

31 Baldur-Felskov B, Dehlendorff C, Munk C, Kjaer SK. Early impact of human papillomavirus vaccination on cervical neoplasia-nationwide follow-up of young Danish women. J Natl Cancer Inst 2014;106:djt460. doi:10.1093/jnci/djt460

32 Gertig DM, Brotherton JM, Budd AC, Drennan K, Chappell G, Saville AM. Impact of a population-based HPV vaccination program on cervical abnormalities: a data linkage study. BMC Med 2013;11:227. doi:10.1186/1741-7015-11-227

33 Brotherton JM, Fridman M, May CL, Chappell G, Saville AM, Gertig DM. Early effect of the HPV vaccination programme on cervical abnormalities in Victoria, Australia: an ecological study. Lancet 2011;377:2085-92. doi:10.1016/S01406736(11)60551-5

34 Niccolai LM, Julian PJ, Meek JI, McBride V, Hadler JL, Sosa LE. Declining rates of high-grade cervical lesions in young women in Connecticut, 2008-2011. Cancer Epidemiol Biomarkers Prev 2013;22:1446-50. doi:10.1158/1055-9965.EPI-13-0272 
35 Luckett R, Feldman S. Impact of 2-, 4- and 9-valent HPV vaccines on morbidity and mortality from cervical cancer. Hum Vaccin Immunother 2016;12:1332-42. doi:10.1080/21645515.2015.11 08500

36 Lew JB, Simms KT, Smith MA, et al. Primary HPV testing versus cytology-based cervical screening in women in Australia vaccinated for HPV and unvaccinated: effectiveness and economic assessment for the National Cervical Screening Program. Lancet Public Health 2017;2:e96-107. doi:10.1016/S2468-2667(17)30007-5
37 Kim JJ, Burger EA, Sy S, Campos NG. Optimal Cervical Cancer Screening in Women Vaccinated Against Human Papillomavirus. J Natl Cancer Inst 2016;109:djw216. doi:10.1093/jnci/djw216

38 Pan J, Kavanagh K, Cuschieri K, et al. Increased risk of HPV-associated genital cancers in men and women as a consequence of pre-invasive disease. IJC, 2018. https://doi.org/10.1002/ijc.3212.

Supplementary table: Distribution of vaccination status and cytology and histology results by year of birth 